\title{
PRÁTICA AGROPECUÁRIA E DEGRADAÇÃO AMBIENTAL NOS MUNICÍPIOS DO ESTADO DE MATO GROSSO DO SUL
}

\author{
Agricultural Practice and Environmental Degradation in the Municipalities of the State of Mato \\ Grosso do Sul
}

\section{RESUMO}

Este trabalho objetiva analisar a relação entre prática agropecuária e a degradação ambiental no estado do Mato Grosso do Sul, no ano de 2006. Especificamente, propõe-se, por meio de análise estatística multivariada, verificar os fatores associados à intensidade da agropecuária, predominantes na determinação do padrão de degradação nos municípios do estado do Mato Grosso do Sul, além de obter índice de degradação ambiental e classificar os municípios quanto ao padrão de degradação. Os resultados indicam que a intensidade de produção agrícola e a sustentabilidade na pecuária no estado são os principais fatores responsáveis por maiores índices de degradação em Mato Grosso do Sul.

Janaína Sudário Pereira

Universidade Federal de Mato Grosso do Sul

janaina_sudario@yahoo.com.br

Matheus Wemerson Gomes Pereira

Universidade Federal de Mato Grosso do Sul

matheuswgp@yahoo.com.br

Renato Luiz Sproesser

Universidade Federal de Mato Grosso do Sul

renato.sproesser@gmail.com

Recebido em: 27/07/2017. Aprovado em: 08/04/2020.

Avaliado pelo sistema double blind review

Avaliador científico: Rafael Eduardo Chiodi

DOI: 10.48142/2238-68902019v21n1-3p119

\begin{abstract}
This work aims to analyze the relationship between agricultural practices and environmental degradation in the state of Mato Grosso do Sul, in 2006. Specifically, it is proposed, through multivariate statistical analysis, to verify the factors associated with the intensity of agriculture, predominant in the Determination of the degradation pattern in the municipalities of the State of Mato Grosso do Sul, besides obtaining an index of environmental degradation and classifying the municipalities as to the degradation pattern. The results indicate that the intensity of agricultural production and the sustainability of cattle ranching in the State are the main factors responsible for higher rates of degradation in Mato Grosso do Sul.
\end{abstract}

Palavras-chave: Análise Fatorial. Sustentabilidade. Exploração Agropecuária.

Keywords: Factor Analysis. Sustainability. Agricultural and Livestock Farming.

\section{INTRODUÇÃO}

A prática agropecuária e sua intensidade de exploração constitui tema polêmico e divide opiniões. No entanto, apesar de todas as críticas à intensidade da exploração agropecuária tradicional, há ainda os que acreditam que o crescimento do agronegócio e, sobretudo da agropecuária, seja apenas via degradação ambiental no vislumbre de uma rentabilidade com resultados positivos. Nessa perspectiva, questionam-se a visão convencional de que os impactos da intensidade de exploração agropecuária nos municípios do Mato Grosso do Sul sejam apenas degradantes.
Tradicionalmente, o desenvolvimento econômico apontava para incompatibilidade entre crescimento econômico e a preservação dos recursos naturais, em especial nos cerrados (CUNHA et al. 2008). Contudo, existe um processo de crescimento tecnológico e mudança socioambiental, ainda que imposto por essa incompatibilidade, e que deve ser observado. Este fato não subestima os desafios a serem enfrentados pelo setor agrícola, sobretudo na prevenção e solução de problemas de degradação ambiental.

Globalmente há um crescente reconhecimento quanto ao papel significativo que as estratégias de adoção 
de tecnologia com práticas sustentáveis desempenharam na determinação do sucesso da agropecuária no Brasil ${ }^{1}$, sobretudo nos cerrados. A fim de estimar adequadamente a intensidade de exploração agropecuária no Mato Grosso do Sul, o objetivo desta pesquisa é analisar a relação entre exploração agropecuária e degradação ambiental nos municípios do estado do Mato Grosso do Sul no ano de $2006^{2}$. Essa análise não pode simplesmente estimar o potencial de intensificação de uma determinada cultura ou produção pecuária em afetar o meio ambiente, mas deve reconhecer o uso de tecnologias com adoção de práticas sustentáveis nos municípios do estado.

A importância do planejamento para atender a demanda crescente por carne, grãos, agroenergia e celulose com ganhos econômicos e socioambientais passa pelo aumento da produtividade e esse é fruto da tecnologia insistentemente utilizada. Agricultores e pecuaristas ao tomarem suas decisões de produção para maximizar o lucro de acordo com a demanda mundial crescente devem utilizar o apoio do planejamento para aumentar a adoção de práticas sustentáveis nos municípios onde as práticas são consideradas baixas no estado. Assim sendo, os profissionais do agronegócio que optam pela continuidade das atividades, sem alterar suas técnicas de produção, sobretudo no que diz respeito à tecnologia sustentável no setor, certamente subestimam as perdas.

O presente trabalho inova na medida em que fornece uma estimativa quantitativa de degradação ambiental, o Índice Geral de Degradação (IGD), a partir da determinação dos fatores associados à intensidade agropecuária predominante no padrão de degradação nos municípios do estado de Mato Grosso do Sul utilizando os dados do censo agropecuário mais recente, considerando a tecnologia com a adoção de práticas sustentáveis na agropecuária do estado.

Ademais, a despeito de trabalhos que constroem índices de degradação ambiental a partir da análise fatorial destacam-se os trabalhos de Lemos (2001), que faz uma análise do Índice de degradação ambiental nas regiões Sub-úmido e Semi-árido do Nordeste; Cunha et al. (2008), que construíram um indicador da degradação ambiental na região dos Cerrados e Campos et al. (2017) que analisaram a degradação ambiental e seus determinantes para o estado de Minas Gerais.

\footnotetext{
${ }^{1}$ A respeito da repercussão internacional desse tema ver as matérias "The miracle of the cerrado" e "How to feed the World" ambas no The Economist de $26 / 08 / 2010$.

${ }^{2} \mathrm{O}$ ano de 2006 foi escolhido por ser o último ano dos dados do censo agropecuário disponível pelo IBGE.
}

Espera-se que os resultados obtidos no presente estudo possam, além de contribuir para o debate sobre sustentabilidade na agropecuária Sul mato-grossense, sejam instrumento de gestão ambiental que possa ser atualizado, na disponibilidade de base de dados mais recente, para avaliar a evolução da degradação ambiental no estado. As informações obtidas pelo IGD poderão auxiliar os legisladores na tomada de decisão quanto aos objetivos de política ambiental de Mato Grosso do Sul.

Este trabalho divide-se em mais três seções, além desta introdução. Na segunda seção é apresentada a metodologia para a construção do índice geral de degradação dos municípios sul-mato-grossenses e a descrição da base de dados do estudo. Na terceira seção encontra-se a discussão e análises dos resultados da pesquisa e por fim, apresentamse as considerações finais com as conclusões, limitações da pesquisa e indicações de políticas ambientais para o Mato Grosso do Sul.

\section{METODOLOGIA}

Jha e Murthy (2003) salientam que o modelo de componentes principais é o método mais indicado para construção de índice de degradação ambiental e sustentabilidade, uma vez que as variáveis são não correlacionadas este fato é muito relevante para análise ambiental dado que as variáveis ambientais normalmente são intimamente relacionadas. Assim, o referencial teórico e analítico que fundamenta este trabalho é baseado na análise fatorial exploratória que utiliza a técnica de componentes principais para a obtenção dos fatores ${ }^{3}$. Além de utilizar este método, o modelo analítico desta pesquisa assume hipóteses que seja possível obter dimensões latentes que descrevem os dados em um número menor de conceitos do que as variáveis individuais originais conforme apontadas por Hair et al. (2009). No que se refere à construção do IGD utiliza-se a adaptação do método de construção de Cunha et al. (2008) com adição de algumas variáveis. As subseções a seguir descrevem a fundamentação teórica e analítica desta pesquisa e apresentam o método de construção do IGD, assim como, as variáveis indicadoras de intensidade de exploração agropecuária e tratamento dos dados.

\subsection{A Análise Fatorial}

O método analítico escolhido para construção do índice de degradação ambiental para o período é o método conhecido como Análise Fatorial. Este modelo

${ }^{3}$ Neste método os fatores são extraídos de forma a maximizar a contribuição destes para a comunalidade. 
de análise engloba um conjunto de técnicas estatísticas, onde a ideia principal se baseia em poder descrever a variabilidade de um conjunto de $p$ variáveis originais $\mathrm{X}_{1}$, $\mathrm{X}_{2}, \ldots, \mathrm{X}_{\mathrm{p}}$ com o menor número de variáveis aleatórias, também chamadas de fatores comuns, e com isso entender melhor como essas variáveis se relacionam (HAIR et al., 2009; MINGOTI, 2013).

Autores como Manly (2008), Mingoti (2013) e Ferreira (2008) apontam que a análise fatorial tem objetivos semelhantes aos da análise de componentes principais, sendo ambas indicadas para se compreender a estrutura de covariância e correlações da população. Mingoti (2013) argumenta que na análise exploratória o pesquisador procurar identificar os fatores relacionados às variáveis originais (o pesquisador não sabe precisar qual o número de fatores que fazem parte do modelo e nem o que eles representam $)^{4}$.

Segundo Hair et al. (2009), com base em suas correlações as variáveis são agrupadas, sendo que cada variável em determinado grupo ou fator, está altamente correlacionada com as demais variáveis. Os mesmos autores apontam a relevância de se compreender o quanto da variância de uma variável é compartilhada com outras variáveis dentro de um fator, em contraposição ao que não pode ser compartilhada. Dessa forma, pode-se dividir em três partes a variação total de qualquer variável: (i) a variância comum ou comunalidade, é entendida como sendo a quantidade de variação comum entre uma variável e todas as outras pertencentes aquele fator; (ii) a variância específica, ou ainda unicidade, é aquela variância que se refere apenas a uma única variável; (iii) a variância de erro ou simplesmente erro, é a parte da variância total atribuída a erros de medição, a falta de confiabilidade na coleta dos dados ou ainda a um componente aleatório (FERREIRA, 2008; HAIR et al., 2009; MINGOTI, 2013).

A variância total é considerada como a soma da comunalidade, com unicidade e o erro. Por não serem explicadas por correlações com outras variáveis, a unicidade e o erro podem integrar uma parcela comum " $\varepsilon$ ". A variância total das variáveis $\mathrm{X}_{1}, \mathrm{X}_{2}, \ldots, \mathrm{X}_{\mathrm{p}}$ pode ser representada na forma matricial por:

$X_{p x 1}=A_{p x r} F_{r x 1}+\varepsilon_{p}$

Em que:

$\mathrm{X}=$ Vetor das variáveis originais;

${ }^{4} \mathrm{~A}$ análise fatorial pode ser também delineada confirmatória, nesta o pesquisador busca verificar a aplicabilidade e a consistência de um modelo pré-especificado aos dados amostrais disponíveis (MINGOTI, 2013).
$\mathrm{F}=$ Vetor dos fatores comuns (comunalidade);

$\mathrm{A}=$ Matriz (pxr) de cargas fatoriais;

$\varepsilon=$ Vetor de fatores específicos (unicidade) mais o erro;

Ferreira (2008, p. 481) aponta que "nas situações reais os parâmetros do modelo fatorial são desconhecidos e precisam ser estimados a partir de uma amostra aleatória de tamanho n". O primeiro fator escolhido vem a maximizar a soma dos quadrados das cargas fatoriais a ele relacionadas. O próximo fator é escolhido com este mesmo intuito, maximizar a soma de quadrados das cargas fatoriais. E assim por diante se dá a opção pelos fatores.

A seleção do número ideal de fatores foi feita pelo o teste Raiz latente. Este determina que fatores cujos valores de Raiz latente sejam maiores do que 1 devem ser selecionados (HAIR et al., 2009). Depois de selecionada a quantidade de fatores, utiliza-se a técnica de rotação ortogonal VARIMAX a qual distribui as cargas fatoriais entre os fatores selecionados. Tal técnica consiste em girar os eixos dos fatores em torno da origem até que alguma outra posição melhor seja alcançada (HAIR et al., 2009) fazendo com que as cargas fatoriais das variáveis sejam significantes em apenas um fator. Portanto, o principal objetivo da rotação dos fatores é tornar o resultado empírico encontrado mais facilmente interpretável, conservando as suas propriedades estatísticas (TABACHINICK e FIDELL, 2007).

O procedimento denominado VARIMAX seleciona a transformação ortogonal $\mathrm{T}$ que maximize $\mathrm{V}$, assim sua fórmula é descrita como:

$V=\frac{1}{p} \sum_{j=1}^{m}\left[\sum_{i=1}^{p} \tilde{a}_{i j}^{* 4}-\frac{1}{p}\left(\sum_{i=1}^{p} \tilde{a}_{i j}^{* 2}\right)\right]$

em que $\tilde{a}_{i j}=\frac{\hat{a}_{i j}^{*}}{\hat{h}_{i}}$ se caracteriza como a raiz quadrada da comunalidade. O que corresponde à maximização de $\mathrm{V}$ é $\mathrm{o}$ "puxar" dos quadrados das cargas sobre cada fator o máximo que for possível, esperando se encontrar grupos definidos de coeficientes para cada coluna de fator.

\subsection{Método de Construção do Î́ndice Geral de Degradação (IGD)}

A construção do Índice Geral de Degradação (IGD) ambiental que está associado ao grau de intensidade da exploração agropecuária, conforme adotado por Cunha et al. (2008), primeiramente utiliza-se os escores fatoriais normalizados $\left(F_{i j}^{*}\right)$, ou seja, utiliza-se uma transformação nos escores fatoriais dos municípios de Mato Grosso do Sul 
de modo que o menor valor seja zero e o maior valor seja um, esta normalização é feita pela expressão algébrica (3):

$F_{i j}^{*}=\frac{F_{i j}-F_{j}^{\min }}{F_{j}^{\max }-F_{j}^{\min }}$,

em que $F_{i j}^{*}$ é o j-ésimo escore fatorial normalizado do

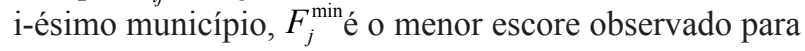
o j-ésimo fator e $F_{j}^{\max }$ é o maior escore observado para o j-ésimo fator.

A construção do IGD apresentado em (4) relaciona o fator normalizado e as raízes características na seguinte forma:

$I G D_{i}=\sum_{j=1}^{p} \frac{\lambda_{j}}{\sum \lambda_{j}} F_{i j}^{*}$,

em que $I G D_{i}$ é o Índice Geral de Degradação do i-ésimo município, o $\lambda_{j}$ é a j-ésima raiz característica, p é o número de fatores extraídos na análise e $\Sigma \lambda_{j}$ é o somatório das raízes características referentes aos $\mathrm{p}$ fatores extraídos.

\subsection{Variáveis Indicadoras de Intensidade de Exploração Agropecuária e Tratamento dos Dados}

$\mathrm{Na}$ análise empírica utilizam-se dados secundários, do censo agropecuário, referentes ao ano de 2006, para realização do estudo. A escolha das variáveis está associada à determinação dos fatores e a disponibilidade de dados existentes de acordo como os objetivos do estudo, uma vez que, as variáveis indicadoras foram escolhidas conforme Hoffmann (1992) e Cunha et al. (2008). A essas, utilizadas por esses autores, acrescenta-se seis (sistemas agroflorestais, plantio direto, recuperação de pastagens, controle de doenças e/ou pragas, rotação de pastagens e tratamento do esterco) com o objetivo de identificar o uso de tecnologia com adoção de práticas sustentáveis da agropecuária nos municípios do Mato Grosso do Sul. As escolhas das práticas sustentáveis na determinação das variáveis acrescentadas foram limitadas pela disponibilidade de dados do Censo Agropecuário de 2006 (IBGE, 2015).

Os fatores foram determinados por meio da seleção de 21 variáveis para os 78 municípios de Mato Grosso do Sul (o mapa de MS encontra-se em anexo - Figura A1), com exceção do município de Paraíso das Águas (n. 58 no mapa da Figura A1 - Anexo) que não foi analisado por ter sido fundado após o censo agropecuário de 2006, logo nesta pesquisa este município será considerado como distrito do município de Costa Rica (n. 27 no mapa da Figura A1 - Anexo).
A área aproveitável dos estabelecimentos utilizada conforme Hoffmann (1992) e Cunha et al. (2008), foram adaptadas às alterações ocorridas no Censo Agropecuário de 2006, neste há o maior detalhamento em relação ao censo agropecuário 1995-1996. A descrição do uso da terra nos estabelecimentos no censo agropecuário de 2005-2006 compreende o somatório das áreas destinadas ao uso de lavouras permanentes e temporárias, pastagens naturais e plantadas, matas naturais e plantadas e sistemas agroflorestais. A variável que representa o número de arados, no Censo de 2006 não há o detalhamento do arado. Por fim, a variável representativa do valor de despesas com combustíveis, não foi observado despesas com lubrificantes apenas o consumo. As variáveis deste trabalho são:

- X1 = área total utilizada com culturas permanentes em relação à área aproveitável dos estabelecimentos;

- X2 = área total utilizada com culturas temporárias/ AA dos estabelecimentos;

- X3 = área total utilizada com pastagens naturais/ AA dos estabelecimentos;

- X4 = área total utilizada com pastagens plantadas/ AA dos estabelecimentos;

- X5 = efetivo bovino em relação à área com pastagens naturais e plantadas dos estabelecimentos;

- $\mathrm{X} 6=\mathrm{n} .{ }^{\circ}$ de tratores/AA dos estabelecimentos;

- $\mathrm{X} 7=\mathrm{n} .^{\circ}$ de $\operatorname{arados} / \mathrm{AA}$ dos estabelecimentos;

- $\mathrm{X} 8=\mathrm{n} .^{\circ}$ de outras máquinas e implementos agrícolas /AA dos estabelecimentos;

- $\mathrm{X} 9=$ n. ${ }^{\circ}$ de máquinas para plantio/AA dos estabelecimentos;

- $\mathrm{X} 10=$ n. ${ }^{\circ}$ de máquinas para colheita/AA dos estabelecimentos;

- X11 = valor de despesas com adubos e corretivos/ AA dos estabelecimentos;

- X12 = valor de despesas com agrotóxicos/AA dos estabelecimentos;

- $\mathrm{X} 13$ = valor de despesas com combustíveis/AA dos estabelecimentos;

- X14 = valor de despesas com energia elétrica consumida/AA dos estabelecimentos;

- X15 = área irrigada/AA dos estabelecimentos;

- $\mathrm{X} 16=$ Sistema agroflorestais/AA dos estabelecimentos;

- $\mathrm{X} 17$ = Plantio direto/AA dos estabelecimentos;

- X18 = Recuperação de pastagens/AA dos estabelecimentos;

- $\mathrm{X} 19$ = controle de doenças e ou pragas/AA dos estabelecimentos;

Organizações Rurais \& Agroindustriais, Lavras, v. 21, n. 1-3, p. 1-19, 2019 
- X20 = Rotação de pastagens/AAdos estabelecimentos;

- X21 = tratamento do esterco/AAdos estabelecimentos.

A seguir são apresentadas as estatísticas descritivas das 21 variáveis utilizadas no estudo para o período de 2006 (Tabela 1).

O modelo de Análise Fatorial e a construção dos escores fatoriais foi estimado usando o software Stata13. O mapa dos fatores e do Índice Bruto de Degradação foram feitos utilizando o software GeoDa.

\section{RESULTADOS}

Inicialmente são estimados os escores fatoriais com o intuito de se diminuir as variáveis encontradas em um número menor de fatores, o estudo, com base nos critérios da Raiz Latente, observa-se que os fatores obtidos por componentes principais acima da unidade e rotacionados pelo método Varimax foram cinco, conforme mostrado na Tabela 2.

TABELA 1 - Estatística descritiva das variáveis

\begin{tabular}{cccccc}
\hline Variável & Obs & Média & Desvio-padrão & Min. & Max. \\
\hline X1 & 78 & 0,0042777 & 0,0047576 & 0 & 0,0224949 \\
X2 & 78 & 0,135429 & 0,171589 & 0,0004188 & 0,6365384 \\
X3 & 78 & 0,1475029 & 0,1357074 & 0,0054565 & 0,730857 \\
X4 & 78 & 0,6719127 & 0,189902 & 0,1824412 & 0,9342913 \\
X5 & 78 & $1,110,082$ & 0,1866662 & 0,4537933 & $1,540,532$ \\
X6 & 78 & 0,0023929 & 0,0018777 & 0,0002479 & 0,0119449 \\
X7 & 78 & 0,0012553 & 0,0011955 & 0,0000695 & 0,0072287 \\
X8 & 78 & 0,003907 & 0,00297 & 0,0002981 & 0,0189091 \\
X9 & 78 & 0,0008981 & 0,0011816 & 0,0000344 & 0,0065675 \\
X10 & 78 & 0,0003233 & 0,0005452 & 0 & 0,0027411 \\
X11 & 78 & 0,0709007 & 0,1845369 & 0,0000193 & $1,507,807$ \\
X12 & 78 & 0,0530341 & 0,1541527 & 0 & $1,017,116$ \\
X13 & 78 & 0,0205442 & 0,0154848 & 0,0016876 & 0,0763114 \\
X14 & 78 & 0,0168485 & 0,0443455 & 0,0004787 & 0,3481387 \\
X15 & 78 & 0,0067629 & 0,0139599 & 0 & 0,0811429 \\
X16 & 78 & 0,0071408 & 0,0163162 & 0 & 0,0918277 \\
X17 & 78 & 0,0888778 & 0,1455063 & 0 & 0,5827035 \\
X18 & 78 & 0,000352 & 0,0007242 & $6,83 \mathrm{e}-06$ & 0,0056396 \\
X19 & 78 & 0,0039666 & 0,0047135 & 0,0003146 & 0,0276364 \\
X20 & 78 & 0,0018628 & 0,0023225 & 0,0000344 & 0,0111622 \\
X21 & 78 & 0,0001502 & 0,0003496 & 0 & 0,0023802 \\
\hline
\end{tabular}

Fonte: resultados de pesquisa, elaborada pelos autores

TABELA 2 - Fatores obtidos pelo método dos componentes principais rotacionados

\begin{tabular}{cccc}
\hline Fator & Raiz Característica $\left(\lambda_{i}\right)$ & Variância Explicada pelo Fator (\%) & Variância Acumulada (\%) \\
\hline 1 & 6,8587 & 32,66 & 32,66 \\
2 & 4,8458 & 23,08 & 55,74 \\
3 & 1,7825 & 8,49 & 64,22 \\
4 & 1,4806 & 7,05 & 71,27 \\
5 & 1,4206 & 6,77 & 78,04 \\
\hline
\end{tabular}

Fonte: Resultados de pesquisa 
A Tabela 2 mostra que os cinco primeiros fatores do grupo de variáveis são responsáveis pela maior porcentagem da variabilidade acumulada $(76,82 \%)$. O teste Kaiser-Meyer-Olkin (KMO), em Anexo (Tabela A1), mostra que o modelo tem um bom ajustamento 0,7541, conforme critério sugerido por Hair et al. (2009). Os resultados apontam que estes são os fatores que mais se destacam quanto à intensidade de exploração agropecuária no estado e cada fator apresenta uma característica relacionada a algumas variáveis do estudo.

A Tabela 3 apresenta as variáveis relacionadas aos fatores expressos na análise, assim como as comunalidades de cada variável em relação aos fatores, os valores em negrito indicam as variáveis mais fortemente associadas a cada fator.

Verifica-se, conforme a Tabela 3, que o Fator 1 está relacionado a tecnologia do sistema de plantio direto (SPD) (X17); este fator também está fortemente correlacionado com os indicadores de exploração temporária da terra (X2); de uso de força mecânica por área explorada $(\mathrm{X} 10, \mathrm{X} 13, \mathrm{X} 9$, $\mathrm{X} 6, \mathrm{X} 8$ ) e uso de tecnologia bioquímica (X11) em ordem de representatividade, indicando que é um fator associado a tecnologia do sistema de plantio direto e intensidade de tecnologia mecânica e bioquímica por área aproveitável. Esse fator será denominado de nível de utilização de plantio direto, intensidade de exploração agrícola do solo e uso das tecnologias mecânica e bioquímica.

O Fator 2, fortemente associado ao manejo e as boas práticas agropecuárias, com destaque para bovinocultura (X19, X20, X21 e X18), de uso de força mecânica por área explorada $(X 7, X 8, X 6)$ e pode ser interpretado como fator representativo de sustentabilidade da pecuária sul-mato-grossense. O Fator 3 também associado a pecuária representativo do efetivo bovino em relação a área com pastagens (X5) e da área total utilizada com pastagens plantadas por área aproveitável (X4) em ordem de representatividade. Este fator será denominado de bovinocultura.

TABELA 3 - Cargas fatoriais após a rotação ortogonal e comunalidades obtidas na Análise Fatorial

\begin{tabular}{ccccccc}
\hline \multirow{2}{*}{ Variável } & \multicolumn{5}{c}{ Fatores } & \multirow{2}{*}{ Comunalidade } \\
\cline { 2 - 5 } & 1 & 2 & 3 & 4 & 5 & 0,6112 \\
X1 & 0,0614 & 0,3198 & 0,0407 & $\mathbf{0 , 6 3 3}$ & 0,3207 & 0,9202 \\
X2 & $\mathbf{0 , 9 4 8 9}$ & 0,1139 & 0,0566 & 0,0166 & 0,0573 & 0,8923 \\
X3 & $-0,1272$ & $-0,1377$ & $-0,9185$ & 0,1163 & 0,0035 & 0,9453 \\
X4 & $-0,7246$ & 0,029 & $\mathbf{0 , 6 3 0 7}$ & $-0,0931$ & $-0,1137$ & 0,7215 \\
X5 & 0,1322 & $-0,0237$ & $\mathbf{0 , 6 8 0 3}$ & 0,4899 & $-0,026$ & 0,9211 \\
X6 & $\mathbf{0 , 7 8 5}$ & 0,5286 & 0,1045 & $-0,1077$ & 0,0543 & 0,8857 \\
X7 & 0,3953 & $\mathbf{0 , 8 4 4 1}$ & 0,1152 & 0,055 & 0,0264 & 0,9274 \\
X8 & 0,6625 & $\mathbf{0 , 6 8 5 9}$ & 0,1316 & 0,0109 & 0,0241 & 0,9326 \\
X9 & $\mathbf{0 , 8 4 2 2}$ & 0,4473 & 0,079 & $-0,1282$ & 0,0239 & 0,9452 \\
X10 & $\mathbf{0 , 9 3 0 7}$ & 0,2473 & 0,023 & $-0,1284$ & 0,0288 & 0,5323 \\
X11 & $\mathbf{0 , 6 9 5 7}$ & $-0,1108$ & $-0,0093$ & 0,1897 & 0,0076 & 0,5616 \\
X12 & 0,4088 & 0,3013 & 0,0271 & $-0,5291$ & 0,1516 & 0,8772 \\
X13 & $\mathbf{0 , 8 4 9 4}$ & 0,3737 & 0,1052 & 0,0509 & $-0,0492$ & 0,5059 \\
X14 & 0,0788 & 0,1022 & $-0,0568$ & 0,0939 & $\mathbf{0 , 6 9 0 8}$ & 0,4299 \\
X15 & 0,3737 & 0,0447 & 0,0144 & $-0,1661$ & $\mathbf{0 , 5 1 0 3}$ & 0,5462 \\
X16 & $-0,1771$ & $-0,1005$ & 0,0044 & 0,0123 & $\mathbf{0 , 7 1 0 3}$ & 0,9589 \\
X17 & $\mathbf{0 , 9 6 9 9}$ & 0,1049 & 0,0372 & $-0,0709$ & 0,028 & 0,6056 \\
X18 & 0,0977 & 0,514 & $-0,0091$ & $\mathbf{0 , 5 5 8 6}$ & $-0,1408$ & 0,9502 \\
X19 & 0,1135 & $\mathbf{0 , 9 6 0 2}$ & $-0,003$ & 0,1185 & 0,0358 & 0,9094 \\
X20 & $-0,0444$ & $\mathbf{0 , 9 2 8 4}$ & $-0,0137$ & 0,2129 & $-0,0018$ & 0,8088 \\
X21 & 0,3065 & $\mathbf{0 , 8 1 3 9}$ & 0,0909 & $-0,196$ & 0,076 &
\end{tabular}

Fonte: Resultados da Pesquisa

Organizações Rurais \& Agroindustriais, Lavras, v. 21, n. 1-3, p. 1-19, 2019 
O Fator 4, associado a intensividade de culturas permanentes e também às práticas de recuperação de pastagens (X1 e X18). Já o Fator 5 associa-se fortemente a tecnologia de Sistemas Agroflorestais (SAFs) e as tecnologias elétrica e hídrica (X16, X14 e X15), em ordem de representatividade, será denominado SAFs.

Após as estimações dos fatores, obtém-se os escores fatoriais dos 78 municípios de Mato Grosso do Sul, a partir de então é possível construir os escores fatoriais padronizados conforme sugerido por Cunha et al. (2008) e apresentado na Tabela A2 (Anexo). Também o Índice Geral de degradação (IGD) foi estimado para cada município levando em conta os escores fatoriais padronizados, conforme mesmo autor é também apresentado na tabela A2 (Anexo). A Tabela 4 apresenta as estatísticas descritivas dos escores fatoriais padronizados $\left(F_{i}^{*}\right)$ e do IGD.

TABELA 4 - Estatísticas descritivas dos escores fatoriais padronizados $\left(F_{i}^{*}\right)$ e do IGD

\begin{tabular}{ccccc}
\hline Variável & Média & Desvio-padrão & Min. & Max. \\
\hline F1* & 0,247462 & 0,195224 & 0 & 1 \\
F2* $^{*}$ & 0,213353 & 0,148797 & 0 & 1 \\
F3* $^{*}$ & 0,755122 & 0,162859 & 0 & 1 \\
F4* $^{*}$ & 0,525846 & 0,144629 & 0 & 1 \\
F5* $^{*}$ & 0,227114 & 0,166222 & 0 & 1 \\
IGD & 0,315981 & 0,096454 & 0,1608888 & 0,6831604 \\
\hline
\end{tabular}

Fonte: Resultado de pesquisa

Na Tabela 4, observa-se que os fatores padronizados $(\mathrm{F} 1 *, \mathrm{~F} 2 *$ e $\mathrm{F} 5 *)$ apresentaram baixa média, menores que 0,25 , o que indica certa homogeneidade na produção agrícola com intensa exploração para determinadas culturas como soja e milho, na média a adoção de tecnologia com práticas sustentáveis estão concentradas em algumas regiões do estado. Os F3* e F4* foram maiores que 0,5 indicando que a atividade da pecuária é mais heterogênea nos municípios sul-mato-grossenses e que na média em Mato Grosso do Sul a prática de recuperação de pastagens é bastante adotada.

O IGD apresentou média de 0,316 , sendo o menor valor em 0,16 e o maior em 0,68 , os resultados do IGD sugerem que a média dos munícipios se encontra mais próximo dos valores mais baixos, ou seja, o IGD é predominantemente baixo no estado. A seguir apresentase uma análise mais detalhada de cada um dos fatores padronizados e do IGD.

\subsection{A Utilização de Plantio Direto, Intensidade de Exploração Agrícola do Solo e Uso das Tecnologias Mecânica e Bioquímica}

Os escores em relação ao primeiro fator normalizado $\left(F_{1}^{*}\right)$, que representa a maior importância na variabilidade total dos dados $\left(32,66 \%\right.$ da variância total, $\lambda_{1}=6,8587$ na Tabela 2) de cada um dos municípios sul-mato-grossense, são apresentados na Figura 1 divididos por quartis. Os municípios que apresentam maiores resultados, em ordem decrescente são os municípios de Aral Moreira, Itaporã, Douradina, Dourados, Fátima do Sul, Laguna de Carapã, Maracaju e Rio Brilhante. Estes, em seus estabelecimentos, fazem uso das técnicas de plantio direto nas lavouras temporárias e utilizam intensivamente tecnologia mecânica e bioquímica. A alta correlação encontrada a adoção do sistema de plantio direto ao Fator 1 corrobora com a expansão desse sistema na década de 1990 no estado após a iniciativa de pesquisas da Embrapa Oeste na década de 1980. Fato este que segundo Richetti (2006), propiciou elevação da produtividade, redução de custos e benefícios socioambientais em Mato Grosso do Sul.

As adoções das técnicas de plantio direto no estado foram em torno de $63 \%$ da área utiliza em lavoura temporária em 2006, os resultados demonstram prática intensiva de exploração do solo na cultura temporária de grãos com destaque para cultura da soja com predomínio da área plantada nesses municípios. Cunha et al. (2008), salientam que a cultura da soja demanda alta tecnologia desde o uso de máquinas e implementos agrícolas no preparo do solo, uso de sementes de qualidade, controle de pragas e ervas daninhas com grandes riscos de degradação ambiental.

Uma particularidade, em grande parte desses municípios, que deve ser considerada é o predomínio da área destinada a pastagens plantadas em ha sobre a área plantada de cultura perene, com exceção da soja. Os municípios Aral Moreira e Douradina utilizam 58\% e $53 \%$, respectivamente, de pastagens naturais em relação à pastagem plantada. Este fato é um indicativo de que as técnicas de plantio direto adotadas são utilizadas não apenas para aumentar a produtividade da soja como também na recuperação de pastagens, uma vez que esse conjunto de técnicas proporciona maior retenção de nutrientes no solo.

A Figura 2 mostra a evolução da produtividade da terra nos períodos de 2003 a 2013 dos municípios de Aral Moreira, Itaporã, Douradina, Dourados, Fátima do Sul, Laguna Carapã, Maracaju e Rio Brilhante, obtidos da Pesquisa Agrícola Municipal do IBGE, do Sistema IBGE de Recuperação Automática (SIDRA) (IBGE, 
2015b). Foram compilados dados sobre a produção agrícola total e a área plantada total para os anos de 2003 a 2013 por municípios, sendo utilizado o volume de produção convertido em toneladas e usadas as áreas utilizadas para o cultivo de lavouras permanentes (em ha) e lavouras temporárias (em ha), em que observa-se evolução na produtividade da terra entre 2003 a 2013 em todos esses municípios, corroborando com a teoria de elevação da produtividade, redução dos custos e benefícios socioambientais em Mato Grosso do Sul.

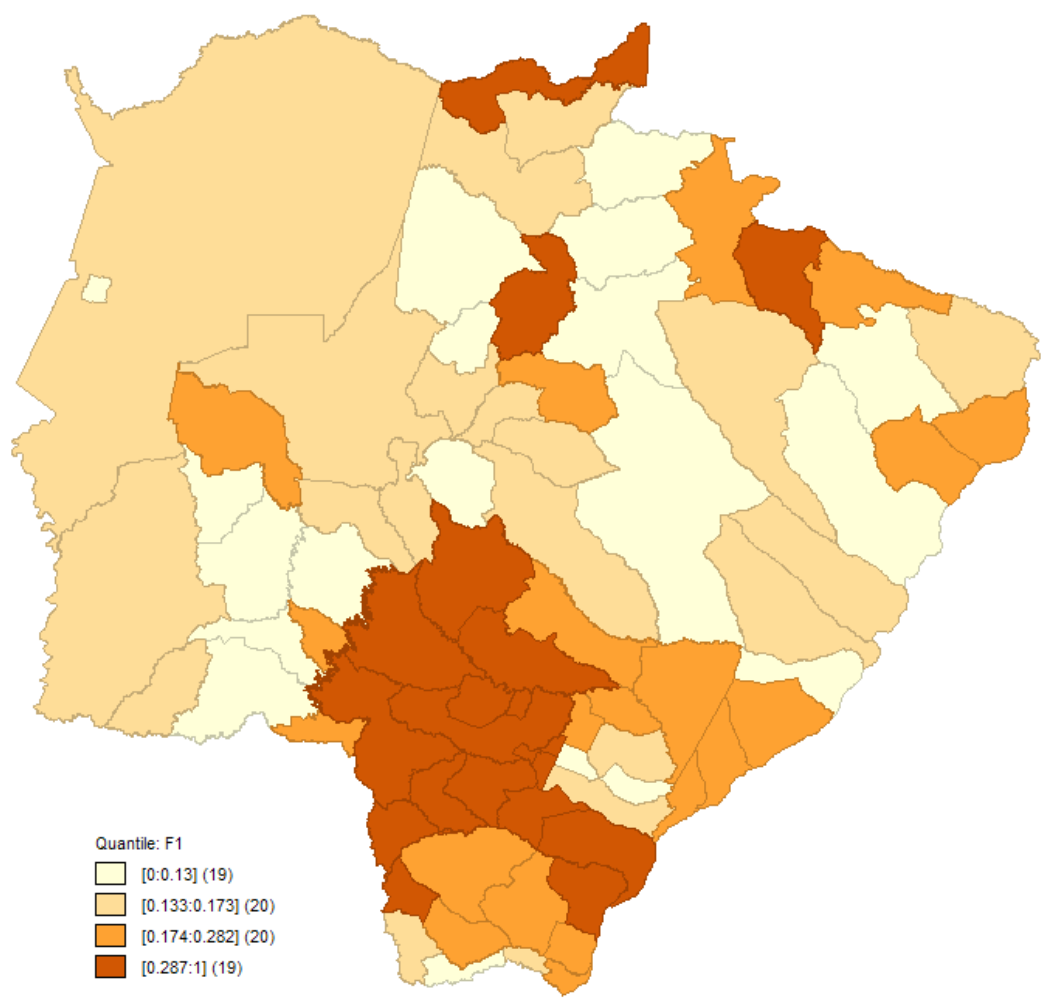

FIGURA 1 - Municípios de Mato Grosso do Sul quanto ao fator 1 normalizado (F1*)

Fonte: Resultados de pesquisa

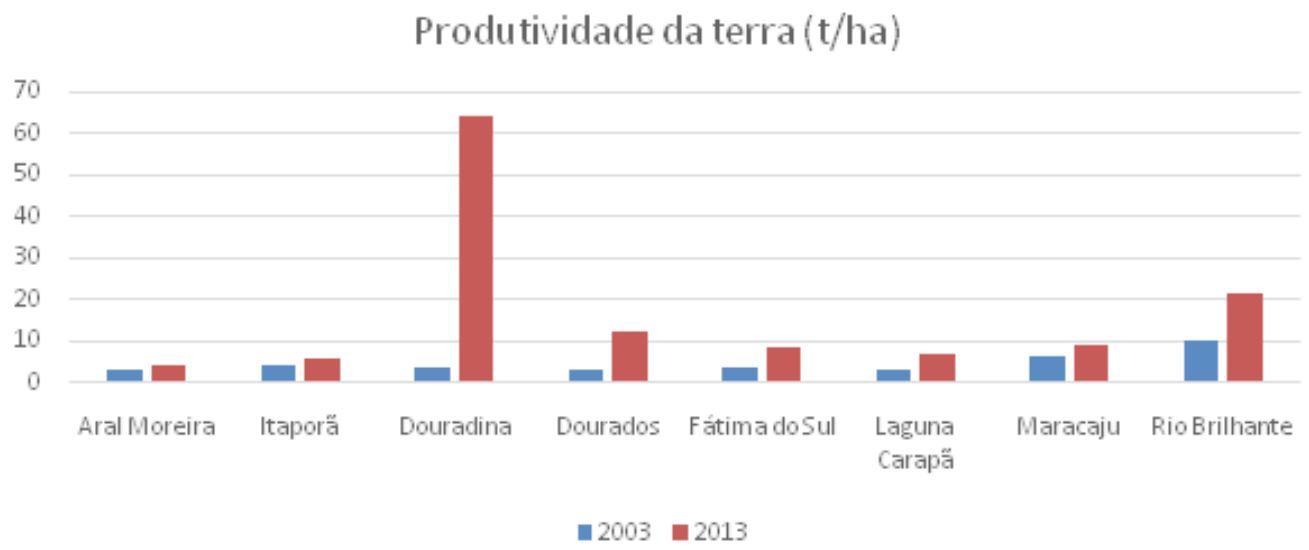

FIGURA 2 - Produtividade da terra (t/ha) de 2003 e 2013, municípios selecionados Fonte: IBGE (2015b). Elaborado pelos autores

Organizações Rurais \& Agroindustriais, Lavras, v. 21, n. 1-3, p. 1-19, 2019 
3.2 Sustentabilidade na Pecuária Sul-Mato-Grossense, com Destaque Especial para Bovinocultura, e Adoção de Sistemas Agroflorestais

A pecuária brasileira mostrou avanços nos últimos anos e tem importante papel na evolução da economia e do desenvolvimento do País, tendo contribuído com 6,87\% do PIB nacional em 2013 (CEPEA, 2015). Em relação à bovinocultura os números são bastante relevantes, e apesar de deter o segundo maior rebanho de gado comercial do mundo, com 209 milhões de bovinos, é o maior exportador mundial de carne bovina, tendo exportado 1,56 milhões de toneladas em 2014 o que equivale a US\$ 7,2 bilhões (ABIEC, 2015). Neste contexto, o estado de Mato Grosso do Sul destaca-se, tendo o terceiro maior rebanho do país, com 21,8 milhões de cabeça, o que equivale a $10,9 \%$ do rebanho nacional (IBGE, 2015).

Já o escore fatorial padronizado $2(\mathrm{~F} 2 *)$ representa a segunda maior variabilidade total dos dados $(23,08 \%$ da variância total, $\lambda_{2}=4,8458$ na Tabela 2$)$. Este é uma estimativa de sustentabilidade na pecuária do estado, uma vez que as variáveis mais significativas explicativas deste fator correspondem às práticas de manejo nos municípios além da tecnologia mecânica empregada. A Figura 3 apresenta sua divisão pelos municípios de Mato Grosso do Sul. Dos 78 municípios apenas seis apresentaram escore fatorial acima de $0.5 \mathrm{em}$ ordem decrescente: Fátima do Sul, Glória de Dourados, Mundo Novo, Ladário, Novo Horizonte do Sul e Vicentina. Entre os municípios que apresentaram os mais baixos escores fatoriais em relação às práticas de manejo na pecuária, ou seja, aqueles cujas práticas são as menos sustentáveis no estado são em ordem crescente Aral Moreira, Laguna de Caporã, Maracaju e Rio Brilhante.

Figura 4 apresenta divisão dos municípios de Mato Grosso do Sul pelos escores fatoriais padronizados F3*, F4* e F5* (painel a, b e c, respectivamente). Na Figura $4 \mathrm{a}$, observa-se para o Fator 3 (F3*), também associado a pecuária, em que mais de três quartos (3/4) de municípios possuem escore fatorial acima de 0.7 , ou seja, dos 78 municípios 73 apresentam escores acima de 0.5. Essas informações obtidas por esse resultado demonstra a importância da Bovinocultura no estado, uma vez que, as variáveis cuja variabilidade mais representam esse fator referem-se ao efetivo bovino em relação à área com pastagens naturais e plantadas dos estabelecimentos (X5) e da área total utilizada com pastagens plantadas por área aproveitável (X4), isto é, trata-se de um indicador de produtividade pecuária Sul mato-grossense. Os 5 municípios que apresentaram escores fatoriais menores que 0.5 são municípios do Pantanal-Sul cuja pecuária é pouco intensiva.

A figura $4 \mathrm{~b}$ apresenta o Fator 4 (F4*) observa-se a representatividade das lavouras permanentes no estado e a prática de recuperação de pastagens. Dos 78 municípios 46 apresentaram escores acima de 0.5 , destes os que mais se destacam em ordem decrescente são: Mundo Novo, Novo horizonte do Sul, Aral Moreira, Taquarussu e Guia Lopes.

Por fim, o Fator 5 (F5*) (Figura 4c) descreve a utilização dos sistemas agroflorestais (SAFs) nos municípios do estado no período estudado. O SAFs é um sistema amplamente aceito como uma abordagem para uso da terra envolvendo mistura deliberada de árvores com culturas e/ou animais (NAIR, 1993 p. 14). O objetivo principal dos SAFs é otimizar o uso da terra, conciliando a produção florestal com a produção de alimentos, conservando o solo e diminuindo a pressão pelo uso da terra para produção agrícola (ENGEL, 1999). Nicodemo e Melloto (2015) salientam que os trabalhos seminais para o desenvolvimento de SAFs em Mato Grosso do Sul tiveram início em 1992, no Departamento de Ciências Agrárias da Universidade Federal de Mato Grosso do Sul. Estes autores afirmam o estabelecimento de parcerias importantes entre centros de pesquisas como as Embrapas Gado de Corte, Agropecuária Centro-Oeste e Pantanal e UFMS/Dourados entre outros favoreceram a disseminação do sistema no estado.

A Figura 4c mostra uma adesão incipiente para este sistema nos municípios. Nestes três quartos dos municípios, (59) tiveram escores menores que 0,249 e apenas os municípios, em ordem decrescente, de Bataguassu, Ponta Porã, Aparecida do Taboado, Amambaí e Nova Andradina apresentaram escores fatoriais maiores que 0,5 , esses possuem maior adesão ao SAFs no estado, de acordo com a base de dados do Censo Agropecuário. E os municípios de Mundo Novo e Itaquiraí representam as menores adesões. Macedo (2009), argumenta sobre a complexidade e eficiência dos sistemas de integração lavoura pecuária (SILPs) em manter a produtividade e recuperação/renovação indireta de pastagens.

Os resultados demonstram disseminação incipiente dos SAFs nos municípios de Mato Grosso do Sul. Esse sistema permite uso mais racional de insumos, além de diversificar a produção e fluxo de caixa dos produtores (MACEDO, 2009). 


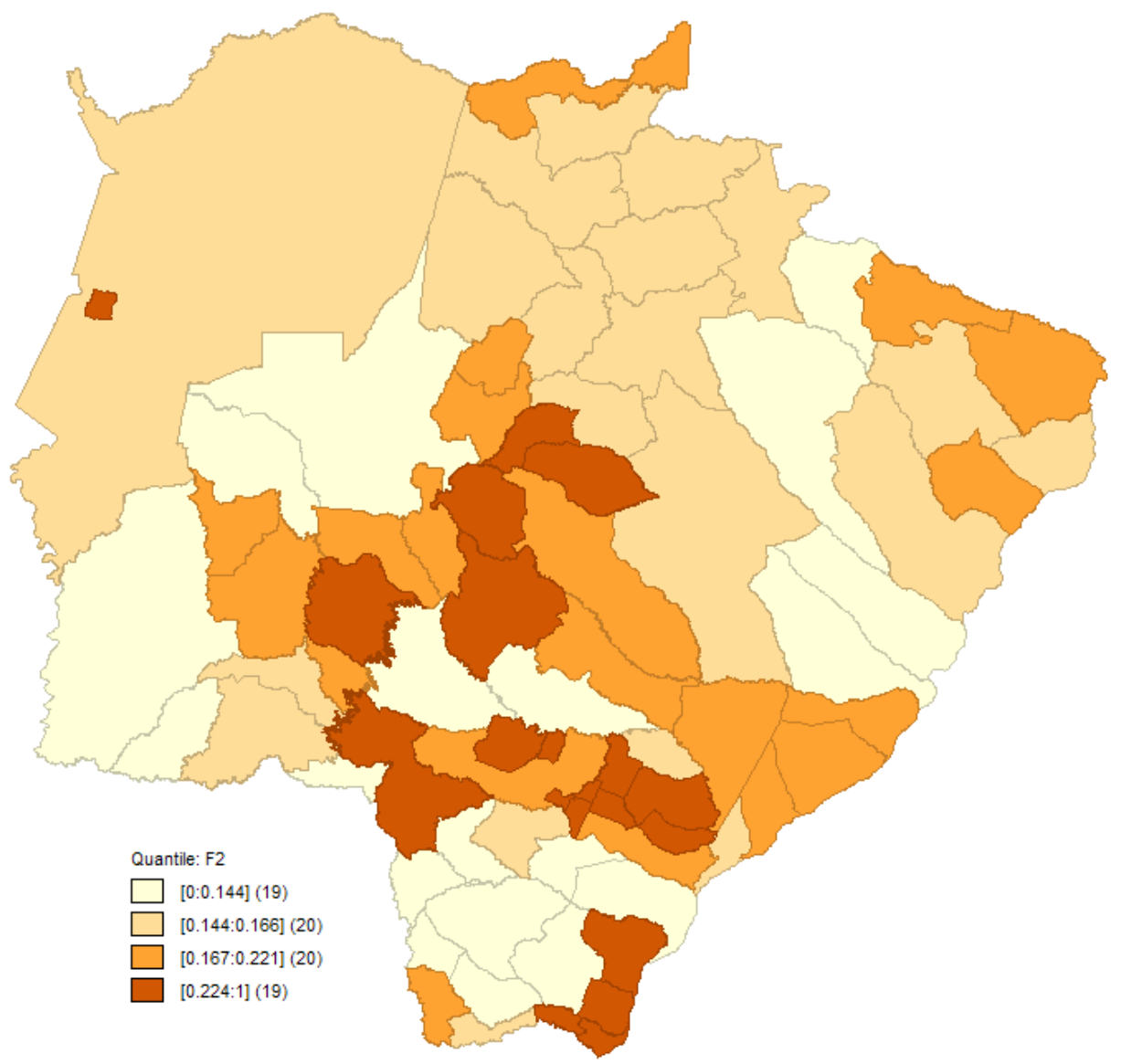

FIGURA 3 - Municípios de Mato Grosso do Sul quanto ao fator 2 normalizado (F2*)

Fonte: Resultados de pesquisa

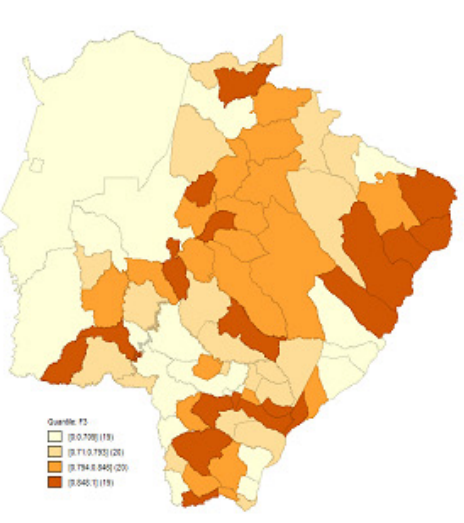

(a)

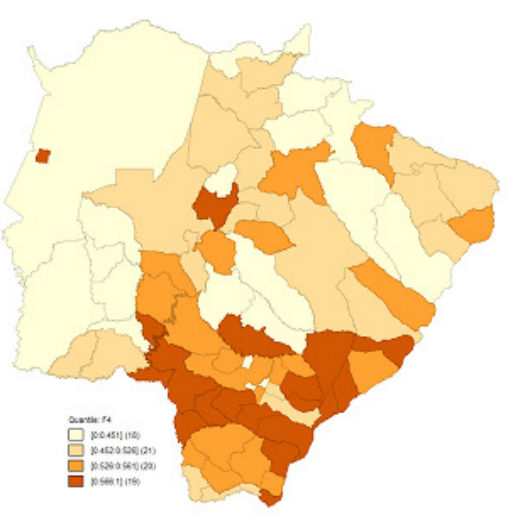

(b)

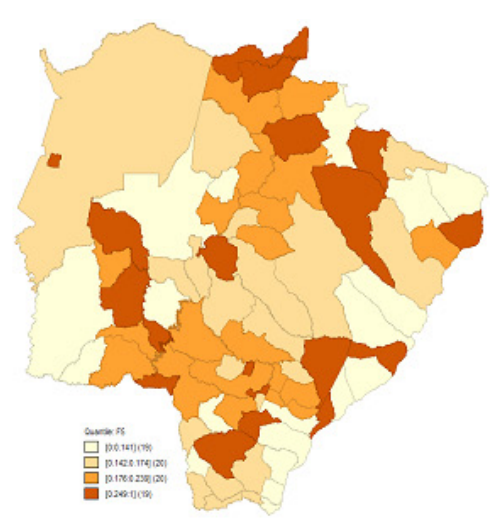

(c)

FIGURA 4 - Municípios de Mato Grosso do Sul quanto aos fatores 3, 4 e 5 normalizado (F3*, F4* e F5*) Fonte: Elaborado pelos autores

Organizações Rurais \& Agroindustriais, Lavras, v. 21, n. 1-3, p. 1-19, 2019 


\subsection{Intensidade de Exploração Agropecuária e Desafios} Ambientais

Afim de ranquear os municípios em termos do potencial de degradação, optou-se por utilizar a intensidade de exploração agropecuária, considerando a adoção de tecnologia com práticas sustentáveis nessas atividades, como uma proxy para a estimação do Índice Geral de Degradação (IGD).

A divisão do IGD pelos municípios de Mato Grosso do Sul pode ser vista na Tabela A2 (em Anexo) em que os cinco municípios apresentaram maiores valores para o IGD possuem suas práticas agropecuárias mais intensas e, portanto, degradantes. Em ordem decrescente o Município de Fátima do Sul apresentou maior IGD, ao observar os resultados dos escores fatoriais padronizados para este município observa-se a maior intensidade quanto às práticas de manejo pecuário e rotação de pastagens, uma vez que foi observada a variável rotação de pastagem no F2* e F4*, mas em F4* apenas rotação de pastagem é relevante já que este município não possui cultivo de lavoura permanente, segundo dados do censo agropecuário de 2006.O F3* demonstra grande importância da bovinocultura no município, bem como grande utilização de pastagens plantadas. A agricultura neste município tem predomínio da monocultura da soja, adoção de plantio direto e uso intensivo de tecnologia mecânica e bioquímica. A adoção de SAFs pode ser observada, uma vez que o escore é incipiente, porém acima da média, assim como o uso de tecnologia hídrica e elétrica. Em suma, este município é intenso tanto na pecuária quanto em agricultura com adoção de tecnologia sustentável crescente na bovinocultura, possui incipiente atividade dos SAFs e uso intensivo de tecnologia mecânica e bioquímica no cultivo agrícola com predomínio de soja.

Os municípios de Itaporã, Aral Moreira, Douradina e Dourados possuem os maiores IGDs após Fatima do Sul. Esses possuem predomínio agrícola com predomínio de produção de soja, utilizam o plantio direto e possuem intenso uso de tecnologia mecânica e bioquímica. A pecuária nesses municípios tem predomínio da bovinocultura de baixa tecnologia uma vez que o escores fatoriais para $\mathrm{F} 2$ * nesses municípios são significativamente baixos ou inexistentes caso de Aral Moreira. Este município tem a maior atividade mecânica e bioquímica, grande atividade pecuária, mas com nenhuma prática de manejo, ou seja, apresenta bovinocultura de baixíssima tecnologia. As adoções dos SAFs foram extremamente baixas nesses quatro municípios.

Entre os municípios que apresentaram menor nível de intensidade agropecuária, ou seja, menor potencial de degradação medidos pelo IGD, esses municípios fazem parte do Pantanal-Sul são eles: Corumbá, Porto Murtinho, Aquidauana e Miranda, e ainda, o município de Rio Verde de Mato Grosso no norte do estado. Souza (2010) afirma que a região do Pantanal Sul apresenta a menor taxa de ocupação com agricultura, porém a pecuária é praticada em quase toda totalidade ocupada. Segundo esta mesma autora essa região é grande produtora de matéria prima para bovinocultura, os bezerros, e que metade do efetivo do rebanho dessa região é explorado nas três fases (cria, recria e engorda), e $26 \%$ é explorado com a finalidade de cria e recria. Esses municípios apresentaram, pelos escores, baixas taxas de manejo na bovinocultura o que os caracteriza como bovinocultura de baixa tecnologia tanto para cria, recria e engorda como para cria e recria. Observa-se também baixa adoção aos SAFs.

A Figura 5 ilustra a distribuição dos municípios em quartis segundo o nível de degradação considerando a utilização da tecnologia com adoção de práticas sustentáveis (IGD). O mapeamento auxilia o direcionamento de políticas públicas, orienta as iniciativas de recuperação indicando municípios prioritários para a implantação de sistemas de intensificação sustentáveis (ANDRADE et al. 2016) com o objetivo de aumentar a eficiência e os índices de produtividades dessas atividades e, portanto, a lucratividade nas atividades aliando produção e conservação dos recursos naturais. A Tabela 5 apresenta a distribuição dos municípios em quartis, a descrição dos municípios contidos em cada quartil, as médias de cada fator normalizado $\left(F_{i}^{*}\right)$ e do IGD, que pode auxiliar na análise dos quartis de municípios.

$\mathrm{Na}$ Figura 5 e Tabela 5, o quarto quartil - IGD alto (mais escuro no mapa), apresenta os municípios com maior nível de intensidade agropecuária e, portanto, de degradação. Neste quartil encontram-se 19 municípios extremamente intensivos em prática agropecuária com elevada degradação. Uma particularidade interessante está nesses municípios serem extremamente intensos ao Fator $1\left(\mathrm{~F} 1^{*}\right)$ onde a variável responsável pela maior variabilidade desse fator é o plantio direto. Contudo, Denardin, Faganello e Santi (2008), em estudos para as lavouras dos estados do Rio Grande do Sul e Santa Catarina, argumentam que falhas na implementação desse sistema levam à degradação do solo e trazem prejuízos econômicos e ambientais. A adoção das técnicas de plantio direto em Mato Grosso do Sul segundo a Federação da Agricultura e Pecuária de MS (FAMASUL) é de aproximadamente 90\% (FAMASUL, 2017), a adoção completa deste sistema nos municípios do estado precisa ser melhor estudada. Os municípios indicados no extrato mais intenso indicado na 
Figura 5 apresentam grande uso de tecnologia química e mecânica as intensificações do uso dessas tecnologias trazem impactos ambientais significantes que devem ser observados. Estes incluem potenciais de degradação do solo e de recursos hídricos que podem comprometer tanto a produtividade agrícola e, portanto, a rentabilidade do produtor, quanto à saúde humana. Foi possível observar grande atividade pecuária, com destaque para bovinocultura, nesses municípios com baixas práticas de manejo, com exceção dos municípios de Fátima do Sul, Novo Horizonte do Sul, Gloria de Dourados, Mundo Novo e Vicentina.

Observa-se ainda, pela Figura 5, que grande parte dos municípios com maiores IGD's tem margem à rodovia BR 163, principal ponto de escoamento da produção agropecuária em Mato Grosso do $\mathrm{Sul}^{5}$, indicando também a forte relação entre a facilidade de escoamento, localização geográfica e IGD.

$\mathrm{Na}$ Figura 5 e Tabela 5, o terceiro quartil, IGD Médio-alto (segundo mais escuro no mapa), encontrase 20 municípios intensivos em prática agropecuária com elevada degradação. Espacialmente encontramse circuncidando os municípios de quartil IGD alto e apresentam quase as mesmas características, porém com valores pouco inferiores principalmente quanto ao fator $1\left(\mathrm{~F} 1^{*}\right)$, indicando que apesar desses municípios apresentarem diversidade de produção agropecuária eles fazem uso de menos técnicas de plantio direto nas lavouras temporárias e utilizam menos intensivamente tecnologia mecânica e bioquímica do que comparativamente aos municípios do quartil IGD alto.

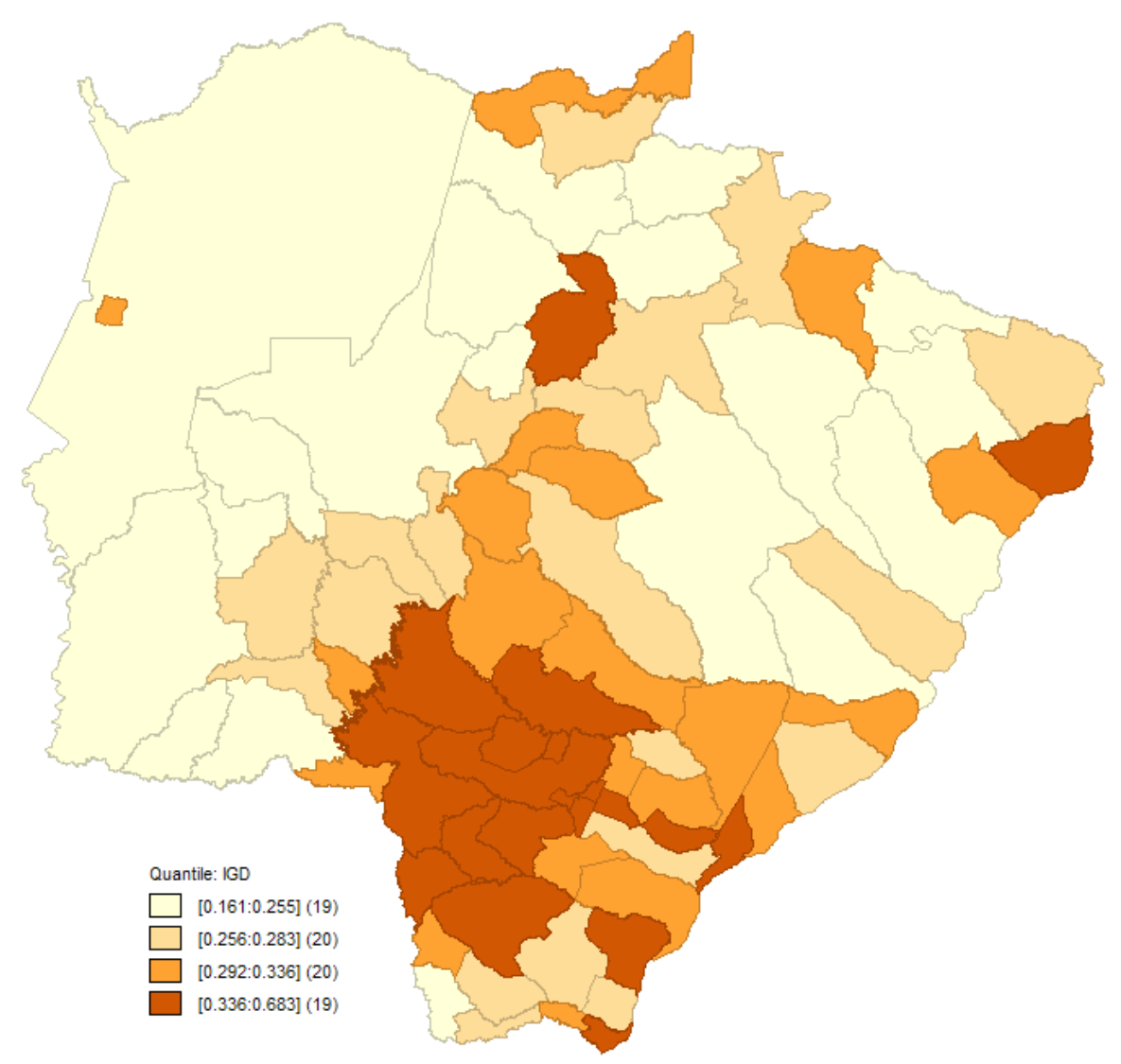

FIGURA 5 - IGD dos Municípios de Mato Grosso do Sul

Fonte: Resultados de pesquisa

${ }^{5}$ Em Mato Grosso do Sul a BR-163 abrange 847 km e atravessa o estado, desde o município de Mundo Novo, na divisa com o Paraná, até Sonora, no Norte do estado e é a principal rota responsável pelo escoamento rodoviário das safras agropecuárias dos estados de Mato Grosso do Sul e outros estados, como Mato Grosso, com destino ao porto de Paranaguá-PR.

Organizações Rurais \& Agroindustriais, Lavras, v. 21, n. 1-3, p. 1-19, 2019 
TABELA 5 - Médias dos fatores padronizados dos municípios quanto a divisão por quartil do IGD

\begin{tabular}{|c|c|c|c|c|c|c|c|c|}
\hline Nome & Municípios & Obs. & $\mathrm{F} 1 *$ & $\mathrm{~F} 2 *$ & F3* & F4* & $\mathrm{F} 5 *$ & IGD \\
\hline IGD Alto & $\begin{array}{l}\text { Fátima do Sul, Itaporã, Aral Moreira, } \\
\text { Douradina, Dourados, Mundo Novo, } \\
\text { Vicentina, Laguna Carapã, Ponta Porã, } \\
\text { Caarapó, Novo Horizonte do Sul, Rio } \\
\text { Brilhante, Maracaju, São Gabriel do Oeste, } \\
\text { Itaquiraí, Aparecida do Taboado, Glória de } \\
\text { Dourados, Taquarussu, Amambaí }\end{array}$ & 19 & 0,4735 & 0,2995 & 0,7978 & 0,5950 & 0,2850 & 0,4519 \\
\hline $\begin{array}{l}\text { IGD } \\
\text { Médio- } \\
\text { alto }\end{array}$ & $\begin{array}{l}\text { Sidrolândia, Deodápolis, Chapadão do Sul, } \\
\text { Ladário, Nova Andradina, Naviraí, Japorã, Sete } \\
\text { Quedas, Nova Alvorada do Sul, Batayporã, } \\
\text { Sonora, Juti, Ivinhema, Bataguassu, Terenos, } \\
\text { Coronel Sapucaia, Guia Lopes da Laguna, } \\
\text { Rochedo, Antônio João, Jaraguari }\end{array}$ & 20 & 0,2216 & 0,2190 & 0,7490 & 0,5475 & 0,2745 & 0,3122 \\
\hline $\begin{array}{l}\text { IGD } \\
\text { Médio- } \\
\text { baixo }\end{array}$ & $\begin{array}{c}\text { Dois Irmãos do Buriti, Costa Rica, Jateí, } \\
\text { Tacuru, Bandeirantes, Iguatemi, Corguinho, } \\
\text { Angélica, Eldorado, Pedro Gomes, Paranaíba, } \\
\text { Anastácio, Anaurilândia, Nioaque, Campo } \\
\text { Grande, Bonito, Selvíria, Camapuã, } \\
\text { Brasilândia, Jardim }\end{array}$ & 20 & 0,1638 & 0,1792 & 0,8087 & 0,5070 & 0,1666 & 0,2698 \\
\hline $\begin{array}{l}\text { IGD } \\
\text { baixo }\end{array}$ & $\begin{array}{l}\text { Caracol, Rio Negro, Paranhos, Água Clara, } \\
\text { Cassilândia, Bodoquena, Coxim, Figueirão, } \\
\text { Alcinópolis, Inocência, Três Lagoas, Ribas } \\
\text { do Rio Pardo, Bela Vista, Santa Rita do } \\
\text { Pardo, Rio Verde de Mato Grosso, Miranda, } \\
\text { Aquidauana, Porto Murtinho, Corumbá }\end{array}$ & 19 & 0,1367 & 0,1571 & 0,6626 & 0,4538 & 0,1831 & 0,2326 \\
\hline
\end{tabular}

Fonte: Resultados de pesquisa

Na Figura 5 e Tabela 5, o segundo quartil, IGD Médio-baixo (terceiro mais escuro no mapa), encontra-se 20 municípios pouco intensivos em prática agropecuária com elevada degradação. Uma característica marcante neste conjunto de municípios e que apresentam maior fator $3(\mathrm{~F} 3 *)$, fator indicativo da bovinocultura, que utilizam pastagens naturais e plantadas, práticas pouco degradantes e baixos $\mathrm{F} 1$ * e F2* indicando que a intensidade de plantio direto e adoção de tecnologia mecânica e bioquímica por área aproveitável encontra-se abaixo da média, além de indicar que manejo e boas práticas agropecuárias abaixo da média. A capital do estado, Campo Grande, encontra-se neste quartil.

Na Figura 5 e Tabela 5, o primeiro quartil, IGD baixo (mais claro no mapa), encontra-se 19 municípios menos degradantes. Na sua maioria encontram-se na região do Pantanal Sul, Centro-Leste e Leste de Mato Grosso do Sul. No caso dos municípios localizados na região Pantanal Sul apresentam características de solo pouco produtivos conforme destacado por Galdino (2010), mais usados para pecuária extensiva. Caracterizam ainda pelo uso do F5* (SAFs) superior aos municípios do quartil IGD médio-baixo.

\section{CONCLUSÕES}

Globalmente há um crescente reconhecimento quanto ao papel significativo que as estratégias de adoção de tecnologia com práticas sustentáveis desempenharam na determinação do sucesso da agropecuária no Brasil, isto também é válido para Mato Grosso do Sul, um estado cujas práticas sustentáveis são bastantes heterogêneas. O presente estudo tem por objetivo analisar a relação entre exploração agropecuária e degradação ambiental nos municípios do estado do Mato Grosso do Sul no ano de 2006.

Os resultados indicam que os cinco primeiros fatores, rotacionados e padronizados, são responsáveis por 78,04\% da variação total dos dados. O primeiro fator é relacionado ao nível de utilização de plantio direto, intensidade de exploração agrícola do solo e uso das tecnologias mecânica e bioquímica municipal. O segundo fator está associado à sustentabilidade da pecuária sul-mato-grossense. Já o terceiro fator é um indicador de intensidade da bovinocultura no estado. $\mathrm{O}$ quarto fator de representatividade das lavouras permanentes 
e práticas de recuperação de pastagens. Por fim, o Fator 5 descreve a utilização dos sistemas agroflorestais (SAFs).

Os municípios que mais se destacam quanto ao primeiro fator apresentam predominante uso técnicas de plantio direto nas lavouras temporárias e utilização intensiva de tecnologia mecânica e bioquímica, destacamse por sua intensidade na produção agrícola, localizam-se em sua maioria no Sudoeste de Mato Grosso do Sul.

O Índice Geral de Degradação (IGD), apresenta relação principalmente quanto a intensidade de produção agrícola e segundo pela sustentabilidade na pecuária no estado, seu valor médio foi de 0,316 , sendo o menor valor em 0,16 e o maior em 0,68 , o que indica um IGD baixo para maioria dos municípios do estado. Os municípios de mais alto IGD fazem uso de plantio direto e grande uso de tecnologia química e mecânica que trazem impactos ambientais significantes que devem ser observados. Em suma, observa-se uma relação direta entre a intensidade de produção agropecuária e os IGD's dos municípios. $\quad$ Em contrapartida, os municípios menos degradantes adotam a prática pecuária extensiva e encontram-se em regiões de solo de baixa produtividade como a região do Pantanal Sul.

A forma com que os agentes econômicos, ou gestores dos recursos, observam a exploração espacial agropecuária em Mato Grosso do Sul, ou seja, a intensidade de produção agropecuária e os IGD's interferem sobremaneira na utilização futura e sustentável dos recursos renováveis e não renováveis. A indicação de municípios com elevado IGD indica que políticas públicas de conscientização ou ação dos gestores, quanto ao uso adequado do plantio direto, a utilização de tecnologias sustentáveis, melhora da informação quanto a degradação do solo, doenças e práticas sustentáveis na pecuária devem ser feitas nestes municípios para não comprometer as produções futuras desses municípios.

\section{REFERÊNCIAS}

ANDRADE, R. G. et al. Recuperação de pastagens no cerrado. AgroANALYSIS, v. 36, n. 2, p. 30-32, fev. 2016.

ASSOCIAÇÃO BRASILEIRA DAS INDÚSTRIAS EXPORTADORAS DE CARNE. Estatísticas. Disponível em: http://www.abiec.com.br/estatisticas. Acesso em: 05 jul. 2015.

CENTRODE ESTUDOS AVANÇADOS EM ECONOMIA APLICADA. PIB Agro CEPEA-USP/CNA. Disponível em: http://cepea.esalq.usp.br/pib. Acesso em: 05 jul. 2015.
CUNHA, N. R. S. et al. A intensidade da exploração agropecuária como indicador da degradação ambiental na região dos Cerrados, Brasil. Revista de Economia e Sociologia Rural, Brasília, v. 46, n. 2, p. 291-323, abr./ jun. 2008.

DENARDIN, J. E.; FAGANELLO, A.; SANTI, A. Falhas na implementação do sistema plantio direto levam a degradação do solo. Revista Plantio Direto, Passo Fundo, v. 18, p. 33-34, 2008.

ENGEL, V. L. Sistemas Agroflorestais: Conceitos e Aplicações. In: ENGEL, V. L. Introdução aos Sistemas Agroflorestais. Botucatu: FEPAF, 1999. 70 p.

FERREIRA, D. F. Estatística multivariada. 1. ed. Lavras: Editora UFLA, 2008. 662 p.

GALDINO, S.; WEILL, M. A. M. Estimativa e análise do fator topográfico (LS) da Equação Universal de Perda de Solo Revisada (RUSLE) para a bacia do Alto Taquaril MS/MT. In: $3^{\circ}$ Simpósio de Geotecnologias no Pantanal, 2010, Cáceres. Anais... Campinas: Embrapa Informática Agropecuária/INPE, 2010. p. 260-269.

HAIR, J. F. et al. Análise multivariada de dados. 6. ed. Porto Alegre: Bookman, 2009. 688p.

HOFFMANN, R. A dinâmica da modernização da agricultura em 157 microrregiões homogêneas do Brasil. Revista de Economia e Sociologia Rural, Brasília, v. 30, n. 4, p. 271-290, out./dez. 1992.

INSTITUTO BRASILEIRO DE GEOGRAFIA E ESTATÍSTICA. Censo agropecuário 2006. Disponível em: http://www.sidra.ibge.gov.br. Acesso em: 05 jul. 2015.

JHA, R.; MURTHY, K. V. A Critique of the Environmental Sustainability Index. Australian National University Division of Economics Working Paper, apr. 2003. Disponível em: http://dx.doi.org/10.2139/ssrn.380160. Acesso em: 12 abr. 2016.

MACEDO, M. C. M. Integração lavoura e pecuária: o estado da arte e inovações tecnológicas. Revista Brasileira de Zootecnia, Viçosa-MG, v. 38, p. 133-146, 2009.

MANLY, B. F. J. Métodos estatísticos multivariados: uma introdução. 3. ed. Porto Alegre: Bookman, 2008. 229 p.

Organizações Rurais \& Agroindustriais, Lavras, v. 21, n. 1-3, p. 1-19, 2019 
MINGOTI, S. A. Análise de dados através de métodos de estatística multivariada: uma abordagem aplicada. Belo Horizonte: Editora UFMG, 2005. 297 p.

NAIR, P. K. R. An introduction to agroforestry. Dordrecht: Kluwer Academic Publishers, 1993. 499 p.

NICODEMO M. L. F.; MELOTTO, A. M. 10 anos de pesquisa em Sistemas Agroflorestais em Mato Grosso do Sul. In: Sistemas agroflorestais: a agropecuária sustentável. ALVES, F. V.; LAURA, V. A.; DE ALMEIDA, R. G. (ed.). Brasília: Embrapa, 2015. cap. 1.
RICHETTI, A. Avaliação dos impactos econômicos do SPD em Mato Grosso do Sul: uma análise do período 2001 a 2006. Dourados: Embrapa Agropecuária Oeste, 2006. 32p.

SOUZA, C. B. M. A Bovinocultura de Corte do Estado de Mato Grosso do Sul: Evolução e Competitividade. 2010. 194 f. Dissertação (Mestrado em Desenvolvimento Econômico). Instituto de Economia, Universidade Estadual de Campinas, Campina, 2010.

TABACHNICK, B. G.; FIDELL, L. S. Using multivariate statistics. Boston: Pearson/Allyn \& Bacon, 2007. 


\section{ANEXOS}

Tabela A1 - Estatística KMO

\begin{tabular}{lll}
\hline Varível & KMO \\
\hline X1 & 0,5349 \\
X2 & 0,7273 \\
X3 & 0,2928 \\
X4 & 0,5399 \\
X5 & 0,4178 \\
X6 & 0,8477 \\
X7 & 0,9047 \\
X8 & 0,8055 \\
X9 & 0,8108 \\
X10 & 0,846 \\
X11 & 0,8356 \\
X12 & 0,8076 \\
X13 & 0,858 \\
X14 & 0,4044 \\
X15 & 0,7703 \\
X16 & 0,1705 \\
X17 & 0,8757 \\
X18 & 0,7987 \\
X19 & 0,6948 \\
X20 & 0,5895 \\
X21 & 0,9176 \\
Geral & 0,7541 \\
\hline
\end{tabular}

Fonte:Resultados de pesquisa

Organizações Rurais \& Agroindustriais, Lavras, v. 21, n. 1-3, p. 1-19, 2019 
TABELAA2 - Escores fatoriais, escores fatoriais padronizados e Índice Geral de Degradação dos municípios de Mato Grosso do Sul

\begin{tabular}{|c|c|c|c|c|c|c|c|c|c|c|c|}
\hline Mur & $\mathrm{F} 1$ & F2 & F3 & F4 & F5 & $\mathrm{F} 1 *$ & $\mathrm{~F} 2 *$ & $\mathrm{~F} 3 *$ & $\mathrm{~F} 4 *$ & $\mathrm{~F} 5 *$ & IGD \\
\hline Á & 5562 & 0,4858 & 231325 & 7 & 08 & 38878 & 41067 & 0,792796 & 0,432271 & 0,257284 & 0,2474 \\
\hline Alcinópolis & 6174 & 74 & 12 & 61 & 48 & 31 & 07 & 16 & 78 & 57 & 0,243892 \\
\hline A & 15814 & 63 & 4 & 0,23122 & 06 & 39 & 77 & 76 & 87 & 38 & 33 \\
\hline A & 58703 & 3 & 88 & 74 & 67 & 59 & 19 & 675 & 14 & 24 & 0,264242 \\
\hline Anauri & 28935 & 3 & 6 & 4 & 8 & 74 & 66 & 6 & 53 & 48 & 0,263411 \\
\hline & 30789 & 6 & 7 & 7 & $-0,3969$ & 55 & 34 & 93 & 36 & 39 & 0,277193 \\
\hline & ,0913 & 5 & 2 & 7 & 0,23022 & 7 & 4 & 53 & 7 & 1 & 0,292821 \\
\hline Apare & $-0,01888$ & 2 & 3 & 6 & 9 & 76 & 2 & 21 & 37 & 31 & 0,366329 \\
\hline na & $-0,48348$ & 7 & 6 & 4 & 1 & 76 & 77 & 05 & 88 & 4 & 0,194453 \\
\hline 14 & 42 & 85 & 22 & 35 & 23 & 1 & 0 & 69 & 15 & 067 & 4 \\
\hline tes & 4 & 76 & 73 & 1 & -1 & 49 & 71 & 58 & 71 & 36 & J \\
\hline 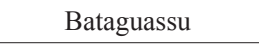 & 749 & ,24612 & ,90376 & 0,65 & 64972 & 869 & 3 & 37 & 24 & 1 & 8 \\
\hline$a$ & 34 & 102 & 93 & 306419 & 821 & 539 & 76 & 37 & 63 & 34 & 3 \\
\hline Belc & 6153 &, 38355 & 21527 &, 412 & 334 & 2734 & 82 & 0,720064 & 59 & 0327 & 16 \\
\hline Bodo & 8932 & 0,05011 & 0,073209 & 0,76459 & $-0,16792$ & 12891 & 0,205897 & 0,767045 & 0,415264 & 0,199201 & 0,246344 \\
\hline onito & 60477 & $-0,26687$ & 0,349804 & $-0,62387$ & 0,340889 & 0,129396 & 0,173643 & 0,812091 & 0,435617 & 0,283777 & 0,257784 \\
\hline Brasilândia & 54101 & $-0,50099$ & 0,78476 & 0,002973 & $-0,51777$ & 0,141844 & 0,138807 & 0,882927 & 0,526276 & 0,141049 & 0,256216 \\
\hline Caarapó & 773342 & $-0,35281$ & 0,824597 & 0,405373 & $-0,22002$ & 0,535094 & 0,160855 & 0,889415 & 0,584474 & 0,190541 & 0,437568 \\
\hline Camapuã & 60888 & $-0,3777$ & 0,557085 & 0,013757 & $-0,19703$ & 0,128594 & 0,157152 & 0,845848 & 0,527836 & 0,194363 & 0,256825 \\
\hline mpo Gran & 51183 & $-0,05894$ & 277181 & $-0,68373$ & $-0,38024$ & 0,147541 & 0,204583 & 0,800264 & 0,426959 & 0,16391 & 0,262067 \\
\hline Iracol & 51116 & $-0,51321$ & 0,74108 & $-0,17148$ & $-0,5531$ & 47671 & 0,136989 & 0,875814 & 0,501045 & 0,135176 & 0,254555 \\
\hline Cassi & 37779 & $-0,24937$ &, 97648 & $-0,20519$ & $-0,47743$ & 73708 & 0,176247 & 0,596094 & ,49617 & 0,147755 & 0,247284 \\
\hline apa & 79504 & $-0,62251$ & 103638 & 0,036323 & 0,144881 & 41073 & 0,120724 & 0,772001 & 0,531099 & 0,251196 & 2167 \\
\hline Corg & 7154 & $-0,1505$ & 238605 & 0,707709 & 0,074603 & 35884 & 0,190959 & 0,793981 & 01 & 514 & 0,277212 \\
\hline Coronel Sapuc & 1404 & 0,54277 &, 17843 & 31 & $-0,62842$ & 781 & 59 & 726064 & 64 & 656 & 0,2 \\
\hline Corumbá & 6 & 88 & 57 & 5 & 1 & 0,15999 & 63 & 0 & 96 & 56 & 39 \\
\hline Costa Rica & 26 & $-0,45584$ & 053085 & 0,71919 & $-0,55$ & 83 & 526 & 768 & 421831 & 35517 & 0,282676 \\
\hline Coxim & 51059 & $-0,37758$ & $-0,39744$ & $-0,40369$ & $-0,0411$ & 0,147782 & 0,157169 & 0,690395 & 0,467461 & 0,220282 & 0,244744 \\
\hline Deodápolis & 03816 & 0,575371 & $-0,25716$ & 0,088127 & $-0,16802$ & 0,240013 & 0,298966 & 0,713242 & 0,538592 & 0,199185 & 0,332353 \\
\hline ois Irmãos do B & $-0,54936$ & 0,052442 & 1,146867 & $-0,29086$ & $-0,47807$ & 0,140213 & 0,221156 & 0,9419 & 48378 & 0,147649 & 0,28303 \\
\hline Doure & 59995 & 0,382421 & $-0,27452$ & $-1,47349$ & 0,197139 & 83891 & 0,270256 & 0,710415 & 0,312737 & 0,259883 & 0,577883 \\
\hline Dourados & 18717 & $-0,09647$ & $-0,39523$ & 0,146 & 8347 & 98 & 98 & 0,690756 & 46964 & 617 & 0,517957 \\
\hline Eldor & 7705 & 0,239 & $-1,7583$ & 0,029 & -0 , & 12897 & 248948 & 0,468767 & 530051 & 0,136234 & 0,273395 \\
\hline Fátim & 81 & 5,286704 & $-0,29361$ & -3 & 0 & 68264 & 1 & 06 & 0 & 0,356049 & 0,68316 \\
\hline Figu & 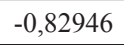 & $-0,42$ & 36 & 9 & 1 , & 85532 & 23 & 49 & 23 & 52 & 0,244553 \\
\hline Glória de Dourados & $-1,26758$ & 1 & 1 & 4 & -0 & 0 & 83 & 88 & 81 & 02 & 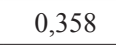 \\
\hline Guia Lopes da Laguna & -( & 6 & 8 & 28 & 0 & 55 & 7 & 4 & 11 & 41 & 46 \\
\hline $\mathrm{I}$ & $-0,24645$ & 3 & 88 & 4 & -0 & 19 & 91 & 99 & 84 & 46 & 07 \\
\hline Inoc & 97 & 22 & 35 & 36 & -0 & 91 & 58 & 53 & 12 & 58 & 43111 \\
\hline Itaporã & 6 & 87 & 13 & 0 , & -0 & 48 & 46 & 73 & 29 & 489 & 0,608563 \\
\hline Itaquiraí & 0,360356 & 0,871513 & $-0,51297$ & 1,38313 & $-1,05717$ & 0,317812 & 0,343032 & 0,671581 & 0,725886 & 0,051389 & 0,37752 \\
\hline
\end{tabular}


TABELA A2 - Continuação

\begin{tabular}{|c|c|c|c|c|c|c|c|c|c|c|c|}
\hline Mun & F1 & F2 & F3 & F4 & F5 & $\mathrm{F} 1 *$ & $\mathrm{~F} 2 *$ & $\mathrm{~F} 3 *$ & $\mathrm{~F} 4 *$ & $\mathrm{~F} 5 *$ & IGD \\
\hline Ivin & 3943 & 137617 & ,09899 & 142923 &, 0074 & 0,170484 & 0,23383 & 0,739001 & 0,691145 & 0,225883 & 0,302894 \\
\hline Japorã & 5487 & 26825 & 336979 & 22838 & 38199 & 139137 & 0,402065 & 0,810002 & 0,492816 & 0,163618 & 0,323927 \\
\hline $\mathrm{J}_{\mathrm{s}}$ & 16617 & 2054 & 388086 & 89748 & 23235 & 156455 & 0,246168 & 0,818325 & 0,538826 & 0,188492 & 0,2922 \\
\hline Jardim & 63168 & $-0,3488$ & 6 & 52828 & 72 & 124 & 52 & 0,885 & 0,449441 & 0,225498 & 0,256 \\
\hline Jateí & 37973 & 7 & 8 & 9 & 9 & 3 & 8 & 26 & 16 & 62 & 28 \\
\hline Juti & 286927 & 3 & 6 & 7 & 6 & 77 & 38 & 2 & 8 & 77 & 6 \\
\hline L & 98148 & 4 & 5 & 7 & 4 & 53 & 2 & 6 & ( & 6 & 6 \\
\hline Lagur & 42017 & $-1,01395$ & 3 & 5 & $-0,6677$ & 3 & 0,06248 & 6 & ( & ( & 2 \\
\hline & 12321 & 8 & $-0,28225$ & 9 & 6 & 3 & 4 & 6 & ( & 7 & 9 \\
\hline & 36196 & 5 & 2 & 6 & 4 & 0,1768 & 3 & 3 & 4 & 1 & 1 \\
\hline Mundo I & 01407 & 2,83444 & $-0,12531$ & 8 & 3 & 0 & & 0,734715 & 1 & 0 & \\
\hline Naviraí & 17106 & 5 & $-0,17441$ & 9 & 4 & 0 & 3 & 7 & ( & 9 & 6 \\
\hline Nioaqu & 66926 & 2 & $-0,1757$ & 8 & 1 & 0 & 3 & 8 & 3 & ( & 3 \\
\hline $\mathrm{N}$ & 1 & 1 & 6009 & 4 & -0 & 0 & 39 & 17 & 18 & 53 & 2 \\
\hline Nova $A$ & 11509 & 2 & 4 & 3 & 1 & 0 & 2 & 5 & 0,65284 & $L^{2}$ & 2 \\
\hline 年 & 038 & 19 & 19 & 10533 & 0 & 0 & 94 & 1 & 50 & 0,2359 & 7 \\
\hline $\mathrm{P}$ & 9543 & 04375 & 599387 & 14838 & $-0,59824$ & 0,150742 & 44 & 0,85 & 0,46 & 7672 & c \\
\hline Parar & 56739 &, 15638 &, 30633 & $-0,12815$ & $-0,48777$ & 0,136694 & 0,190084 & 0,705234 & 0,507312 & 0,146036 & 0,248614 \\
\hline Pedro & 39846 & $-0,40872$ & 0,70802 & $-0,04977$ & $-0,30754$ & 0,169672 & 0,152537 & 0,87043 & 0,518648 & 0,175993 & 0,272903 \\
\hline nta & 13254 & 125458 & 0,41442 & 0,503768 & 4,129033 & 0,386706 & 0,232021 & 0,68763 & 0,598705 & 0,91345 & 0,438515 \\
\hline rto $N$ & 51032 & $-0,48072$ & $-3,00592$ & $-0,67595$ & $-0,59565$ & 0,147836 & 0,141822 & 0,265582 & 0,428084 & 0,128104 & 0,182474 \\
\hline Ribas do & 6222 & $-0,45427$ & 0,394549 & $-0,3901$ & $-0,39038$ & 0,125994 & 0,145759 & 0,819378 & 0,469426 & 0,162224 & 0,241426 \\
\hline $\mathrm{B}$ & 26001 & $-0,8203$ & 0,126291 & 0,678837 & 0,050661 & 0,525852 & 0,091294 & 0,77569 & 0,624025 & 0,235535 & 0,408236 \\
\hline io Negro & 4861 & 11121 & 71318 & 51672 & 01 & 8 & 805 & 0,848167 & 0,451113 & 25 & 025 \\
\hline $\begin{array}{r}\text { Rio Verd } \\
\mathrm{Gr}\end{array}$ & $-0,60629$ & + & 等 & 7 & 9 & 9 & 6 & 7 & 7 & 1 & 7 \\
\hline Rocl & 2978 & 71657 & 18754 & 14 & $-0,42088$ & 0 & 75 & 24 & 0,47 & 54 & 0,2 \\
\hline $\mathrm{S}$ & 44 & 7512 & 99 & 72 & -0 & 4 & 56 & 78 & 86 & 36 & 0 \\
\hline São Gabriel do Oeste & 4 & 19 & 5 & 5 & -0 & 12 & 9 & 15 & 02 & 76 & \\
\hline Selvíria &, 60041 & 9 & 5 & 6 & $-0,4923$ & 7 & 2 & ( & 0,4902 & 32 & ( \\
\hline Sete Quedas & 074 & 202 & 1 & 6 & -( & 5 & 6 & 7 & 34 & 8 & 17 \\
\hline$S$ & 4 & 2 & 4 & 1 & 6 & 6 & & 0,768647 & 8 & 1 & 8 \\
\hline S & 07445 & 7 & 4 & - & 4 & 0 & 2 & 77 & 68 & 78 & 1 \\
\hline Tacuru & 18897 &, 54092 & 188 & 99 & -0 & 71 & 65 & 94 & 66 & 68 & 66 \\
\hline Taquarus: & 11278 & $-0,4313$ & 28921 & 55669 & 0,832599 & 0,269479 & 177 & 0,857548 & 0,837617 & 36551 & 0,357525 \\
\hline Terenos & ,65717 & 494621 & 0,445619 & 0,128635 & 0,285654 & 0,119166 & 0,286951 & 0,827695 & 0,54445 & 0,274596 & 0,297741 \\
\hline rês Lagoas & $-0,6673$ & $-0,41993$ & 0,730894 & $-0,58698$ & $-0,41003$ & 0,117189 & 0,150868 & 0,874155 & 0,440952 & 0,158958 & 0,242354 \\
\hline Vicentina & 344593 & 2,06952 & 754028 &, 236759 & $-0,34262$ & 0,314735 & 0,521292 & 0,877922 & 0,560088 & 0,170162 & 0,446702 \\
\hline
\end{tabular}

Fonte: Elaborado pelos autores. Resultados da pesquisa

Organizações Rurais \& Agroindustriais, Lavras, v. 21, n. 1-3, p. 1-19, 2019 


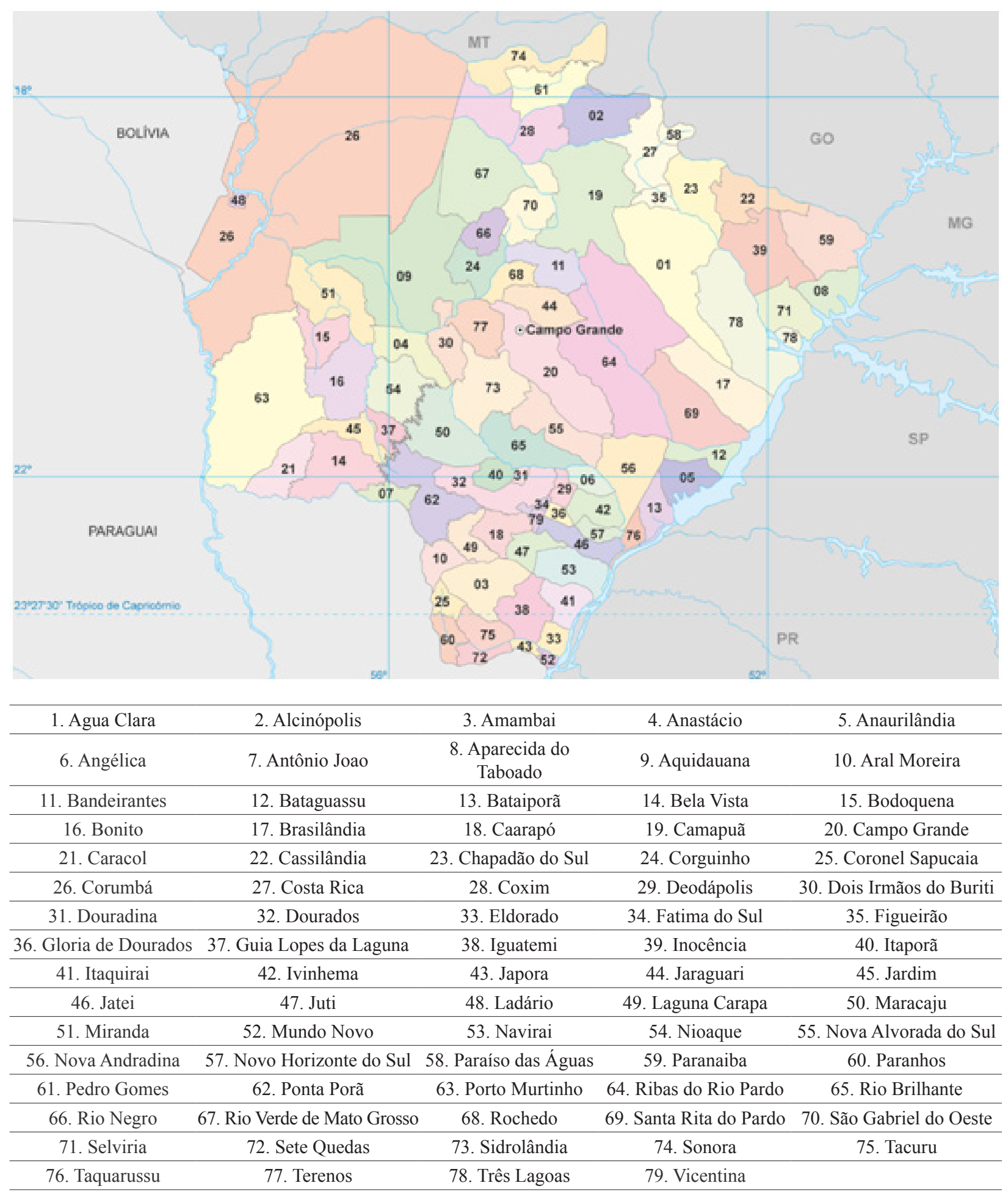

FIGURA A1 - Mapa dos municípios de Mato Grosso do Sul

Fonte: IBGE

Organizações Rurais \& Agroindustriais, Lavras, v. 21, n. 1-3, p. 1-19, 2019 